\title{
To $\mathrm{B}$ or not to $\mathrm{B}$ : How is hepatitis $\mathrm{B}$ spread and what can be done?
}

\author{
SAMUEl S LEE, MD, FRCPC
}

Were my wife's liver infected as her life, She would not live the running of one glass

Shakespeare, The Winter's Tale

\section{$\mathrm{H}$} EPATITIS B IS CURRENTLY ONE OF THE MOST COMMON chronic viral afflictions in the world - an estimated $300,000,000$ people carry the virus (1). In Canada, the rise in reported cases of hepatitis B since 1974 has been alarming; the number of cases per 100,000 population rose from 0.5 in 1974 to five in 1980 and to 13 in 1989 (2). It is accepted that reported cases only represent approximately a tenth of all cases due to under reporting and subclinical presentations $(1,3)$.

We have learned much about hepatitis B over the past 25 years since Dr Blumberg and colleagues first found the virus in Australian aboriginals, which led to the now outmoded term 'Australia antigen' to describe the hepatitis B surface antigen (HBs Ag). Indeed, with the advent of molecular biological methods over the past decade, we have obtained many insights into how the virus infects liver cells, replicates and induces liver disease. Despite the proliferation of knowledge, many questions about its epidemiology remain unanswered. It is accepted that the predominant mode of transmission, especially in economically underdeveloped countries, is 'vertical' transmission, ie, from mother to infant at time of birth or shortly thereafter $(1,3,4)$. However, it is clear that transmission in the prenatal period cannot explain the entire picture, and we now know that this intrafamilial spread of hepatitis B plays a major role. In this regard, careful family studies, such as that of Szilagyi and colleagues (page 23), have helped illuminate the epidemiology of hepatitis B transmission.

Several observations in the report of Szilagyi et al are of interest. One is the apparent decrease in carriage rates with successive generations. This phenomenon has been noted in

Department of Medicine, University of Calgary, Calgary, Alberta Correspondence and reprints: Dr SS Lee, 3330 Hospital Dr NW, Calgary, Alberta T2N 4NI. Telephone (403) 220-3245, Fax (403) 2833028 other studies $(5,6)$. It is unclear why this should occur, but it likely is related to improvement in socioeconomic status. Exactly how low socioeconomic status renders a person susceptible to hepatitis B is unknown, but this susceptibility has been observed with several other infectious diseases, such as hepatitis $C$, tuberculosis and infant diarrhea. One might speculate that poverty is associated with malnutrition, more frequent sharing of personal items such as toothbrushes and razors, and lower hygienic standards. Whatever the mechanism, these observations should provide yet more compelling incentives to avoid poverty.

The source of hepatitis B in the second generation of the presented family appeared to be the father. Intrafamilial clustering related to paternal transmission is relatively uncommon and likely relates to subclinical infection in the spouse or horizontal transmission, again related to lower sociocconomic status.

This report underscores the importance of obtaining a careful family history in patients with hepatitis B. Indeed, 30 to $40 \%$ of persons found to be positive for HBsAg adamantly deny any of the known risk factors $(3,7)$, and it is possible that subclinical intrafamilial spread may account for a significant percentage of these cases. In HBsAg-positive patients who do not belong to a high risk group, a strong argument can be made for serological study of family members.

$A$ vaccine against hepatitis $B$ now exists. Although the first vaccine was plasma-derived, this generally has been superseded by vaccines produced by recombinant DNA technology. Antigenic determinants of HBsAg are now produced by genetically engineered yeast cells. This author was pleased to learn this because he previously thought that yeast only served one useful function, in the production of certain beverages. In some other countries, mass production techniques using recombinant methods enable the vaccine to be manufactured for as little as $\$ 1$ per dose.

It is gratifying to note in the Szilagyi report that three of the infants in the current generation were vaccinated. Without intervention, approximately 80 to $90 \%$ of mothers positive for hepatitis $\mathrm{Be}$ antigen ( $\mathrm{HBeAg}$ ) will transmit the virus to their offspring $(8-10)$. Vaccination will reduce the trans- 
mission rate to no more than $15 \%$ and perhaps much less depending on maternal levels of hepatitis B DNA $(9,10)$. It is imperative that infants and children whose immune systems are still immature not be exposed to the B virus because $90 \%$ of infants will become chronic carriers after an acute attack of hepatitis B compared with only 5 to $10 \%$ of adults $(1,3,11)$. Children exposed to the B virus will have age-dependent intermediate rates of chronicity from 40 to $80 \%(3,11)$.

It is clear that selective screening of pregnant mothers, followed by selective vaccination of newborns, will not succeed in significantly decreasing hepatitis B carriage rates. Studies $(12,13)$ have shown that limiting screening of $\mathrm{HBs} \mathrm{Ag}$ to mothers in high risk groups, eg, intravenous drug users or their sexual partners, those with multiple sexual partners, multiply transfused individuals or immigrants from endemic regions, fails to detect approximately one-half of the $\mathrm{HBsAg-}$ positive women. It is not surprising that many women are reticent about admitting to some of these activities given the attached stigma. Even if all high risk mothers could be identified, selective vaccination of neonates would only be partially effective because there is no way of predicting who will eventually end up in a high risk group.

It thus comes down to a question of universal vaccination. Since no animal reservoir of human hepatitis B exists, we have the opportunity to eradicate this virus completely (as occurred with the smallpox virus in 1977). This may seem like a wildly implausible fantasy given that $5 \%$ of the world's population currently carries this virus. However, at present over 50 countries, including Canada, have either approved or commenced a mass vaccination program using a low cost recombinant vaccine. In many of these countries hepatitis B

\section{REFERENCES}

1. Maynard JE, Kane MA, Alter MI, Hadler SC. Control of hepatitis B by immunization: Global perspective. In: Zuckerman AJ, ed. Viral Hepatitis and Liver Disease. New York: Alan R Liss, 1988:967-9.

2. Hepatitis B in Canada: Surveillance summary 1980-1989. Can Dis Weekly Rep 1991;17:166-71.

3. Margolis HS, Alter MJ, Hadler SC. Hepatitis B: Evolving epidemiology and implications for control. Sem Liver Dis 1991;11:84-92.

4. Stevens CE, Beasley RP, Tsui J, Lee WC. Vertical transmission of hepatitis B antigen in Taiwan. N Engl J Med 1975;292:771-4.

5. Kashiwagi S, Hayashi J, Nomura H, Kajiyama W, Iketmatsu H, Noguchi A. Changing pattern of intrafamilial transmission of hepatitis B virus in Okinawa, Japan. Am J Epidemiol 1988; $127: 783-7$.

6. Stroffolini T, Mattia DD, Compagnone A, Arcamone A, Altomare M, Schettini F. Age-specific prevalence of hepatitis $B$ virus infection among children in an endemic area in Southern Italy. Pediatr Infect Dis 1990;9:407-10.

7. Alter MJ, Hadler SC, Margolis HS, et al. The changing epidemiology of hepatitis B in the United States: Need for alternative vaccination strategies. JAMA 1990;263:1218-22.

8. Okada M, Kamiyama I, Inomata M, Imai M, Miyakawa Y, Mayumi E. E antigen and anti-e in the serum of asymptomatic carrier rates are more than $10 \%$; universal vaccination programs would be expected to decrease dramatically these rates, albeit over a generation or two.

In this country, the Canadian Liver Foundation has been spearheading efforts to implement universal vaccination. Recently the Canadian Pediatric Society and the National Advisory Committee on Immunization issued position papers supporting universal vaccination $(14,15)$. Although the mechanics of implementing the program in Canada have yet to be finalized, several feasible protocols have been proposed. These include universal vaccination of newborns, or through school vaccination programs. The former option might be preferable, since studies show that up to $60 \%$ of infants born to $\mathrm{HBeAg}$-positive mothers who are not infected at birth become infected by the age of five years (11). Therefore, starting vaccination at school age may already be too late. In Canada, health care delivery is generally under provincial jurisdiction, so the final responsibility of implementing the programs rests with provincial health ministries. As the people who eventually end up treating hepatitis B-afflicted patients, it behooves us to start lobbying health ministers for action.

Over four centuries ago, Shakespeare recognized the dangers of viral hepatitis, as evidenced by the beginning quotation. Perhaps a fitting end would be this slightly modified version of Hamlet's soliloquy (with apologies to the Great Bard):

To $B$ or not to $B$ : That is the question. Whether 'tis nobler in the hepar To suffer the slings and arrows of outrageous hepatitis, Or to take arms against a sea of viruses, and by vaccination end them?

carrier mothers as indicators of positive and negative transmission of hepatitis B to their infants. N Engl J Med $1976 ; 294: 944-9$

9. Xu ZY, Liu CB, Francis DP, et al. Prevention of perinatal acquisition of hepatitis virus carriage using vaccine: Preliminary report of a randomized double-blind placebo controlled and comparative trial. Pediatrics 1985;76:713-8.

10. Wong VCW, Ip HMH, Reesing HW, et al. Prevention of the HBs AG carrier state in newborn infants of mothers who are chronic carriers of $\mathrm{HBs} \mathrm{Ag}$ and $\mathrm{HBeAg}$ by administration of hepatitis B vaccine and hepatitis B immunoglobulin. Lancet 1985;i:921-6.

11. Beasley RP, Hwang LY. Postnatal infectivity of hepatitis B surface antigen-carrier mothers. J Infect Dis 1983;147:185-90.

12. Kumar ML, Dawson NV, McCullogh AJ, et al. Should all pregnant women be screened for hepatitis B? Ann Intern Med 1987;107:273-7.

13. Jonas MM, Schiff ER, O'Sullivan MJ, et al. Failure of Centers for Disease Control criteria to identify hepatitis B infection in a large municipal obstetrical population. Ann Intern Med 1987;107:335-7.

14. Canadian Pediatric Society. Hepatitis B in Canada: The case for universal vaccination. Can Med Assoc J 1992;146:25-8.

15. National Advisory Committee on Immunization. Universal vaccination for hepatitis B. Can Med Assoc J 1992;146:36. 


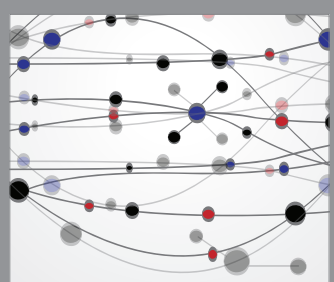

The Scientific World Journal
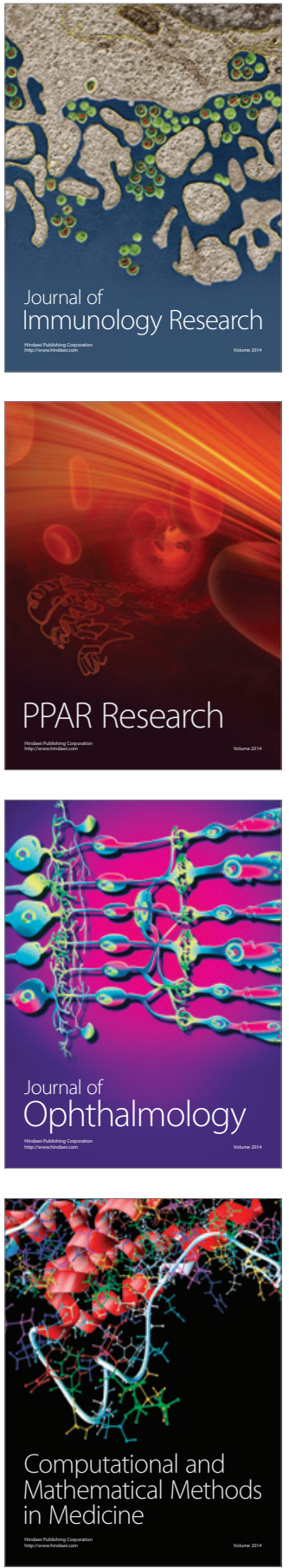

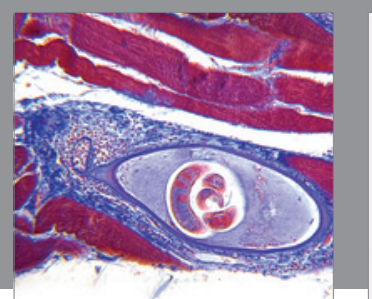

Gastroenterology Research and Practice

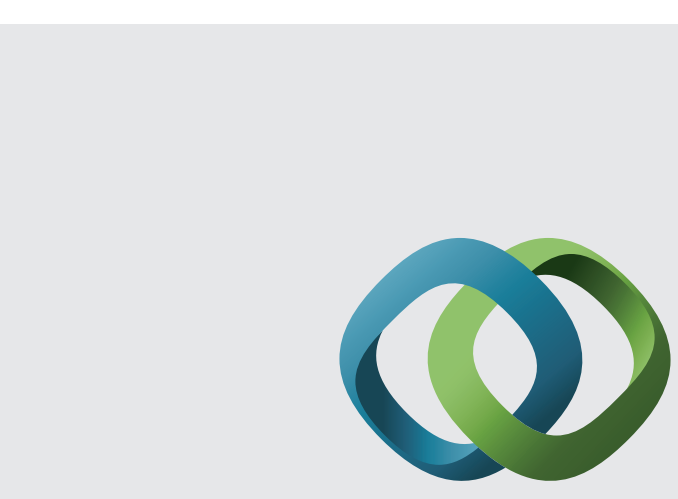

\section{Hindawi}

Submit your manuscripts at

http://www.hindawi.com
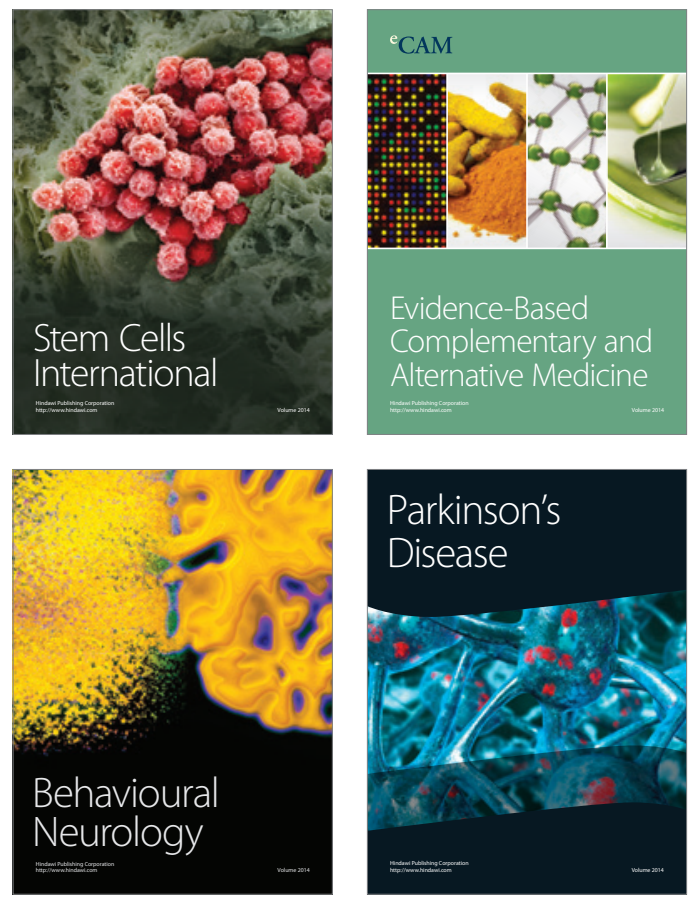
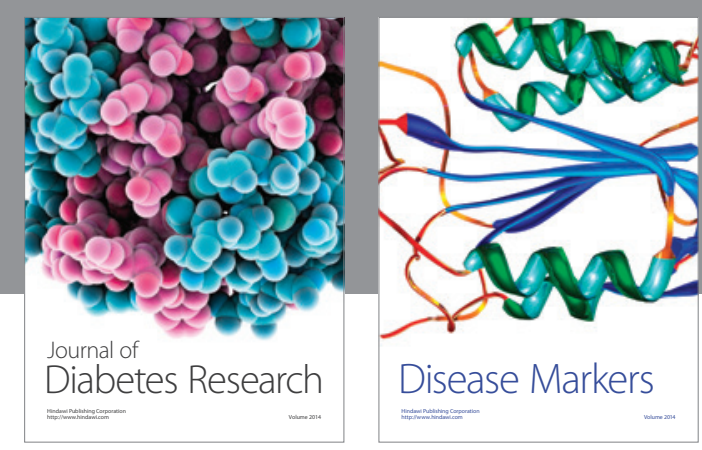

Disease Markers
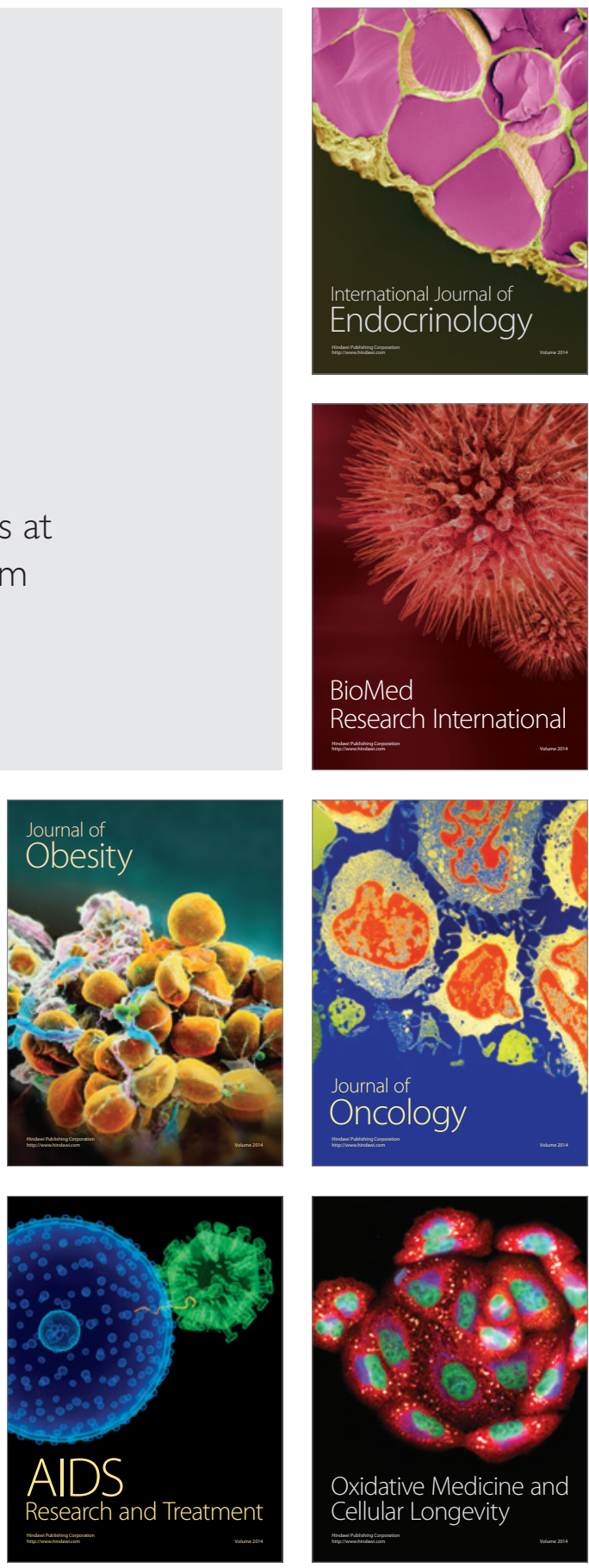